\begin{tabular}{|l|c|c|c|c|}
\hline $\begin{array}{l}\text { Cuadernos de Investigación Geográfica } \\
\text { Geographical Research Letters }\end{array}$ & 2020 & N $^{\circ} 46(2)$ & pp. 603-631 & eISSN 1697-9540 \\
\hline
\end{tabular}

\title{
VALORACIÓN DE SERVICIOS ECOSISTÉMICOS PARA LA IDENTIFICACIÓN DE ESTRUCTURAS ECOLÓGICAS METROPOLITANAS: EL CASO DE CALI, COLOMBIA
}

\author{
M. TABARES-MOSQUERA ${ }^{1}$, E. ZAPATA-CALDAS ${ }^{1,3 *}$, \\ O. BUITRAGO-BERMÚDEZ ${ }^{2}$
}

\begin{abstract}
${ }^{1}$ Grupo de investigación “Territorios”, Departamento de Geografía, Universidad del Valle, Cali, Colombia ${ }^{2}$ Departamento de Geografía, Universidad del Valle, Cali, Colombia. ${ }^{3}$ Facultad de Ciencias Naturales y Exactas, Universidad del Valle, Cali, Colombia.
\end{abstract}

RESUMEN. El objetivo de la presente investigación fue valorar -con base en técnicas de análisis espacial y conocimiento experto- la capacidad de las coberturas de la tierra para proporcionar servicios ecosistémicos (SE) en el sistema socioecológico (SSE) "área de influencia metropolitana de Cali". De esa manera, fue posible identificar la estructura ecológica metropolitana del SSE en mención, para así establecer una línea base a partir de la cual se podrá identificar en el futuro el nivel de conservación o fragmentación de la estructura ecológica metropolitana. La aplicación de la metodología requirió el uso de métodos de investigación mixtos. En este sentido, i) se definió el área del SSE a partir de la combinación de criterios urbano-funcionales y ecológicos-biofísicos; ii) se definieron los criterios para establecer la unidad de análisis y realizar la clasificación de coberturas de la tierra del área definida a escala 1:25.000; y iii) se realizó la valoración de SE a partir de una consulta a expertos pertenecientes a instituciones de carácter académico, administrativo y científico acerca de la capacidad de proporcionar y demandar SE presentes en las coberturas de la tierra que componen el SSE. Se encontró que la estructura ecológica metropolitana está compuesta por diez coberturas de la tierra naturales y seminaturales, las cuales tienen capacidad de proporcionar SE culturales (nivel alto), de regulación (niveles alto y medio) y de aprovisionamiento (nivel bajo). Además, como era de esperar, se validó la percepción de que la zona plana del SSE -la cual concentra las actividades productivas, económicas y de servicios-es claramente la demandante, mientras que las áreas ubicadas en la periferia-i. e. piedemontes y cordilleras Oriental y Occidental-son las proveedoras. Finalmente, los resultados de esta investigación demuestran una vez más que, desde el ángulo académico, hay maneras novedosas para fortalecer los procesos de formulación de lineamientos para la planificación y gestión ambiental de los SSE de carácter metropolitano a partir de la combinación de información espacial y conocimiento experto. 


\title{
Valuation of Ecosystem Services for the Identification of Metropolitan Ecological Structures: the Case of Cali, Colombia
}

\begin{abstract}
The aim of this research was to assess-based on spatial analysis techniques and expert knowledge-the capacity of land covers to provide ecosystem services (ES) in the socioecological system (SES) "metropolitan area of influence of Cali". In this manner, it was possible to identify the metropolitan ecological structure of said SES in order to establish a baseline from which its level of conservation or fragmentation can be identified in the future. The application of the methodology required the use of mixed research methods. In this regard, $i$ ) the SES area was defined from the combination of urban-functional and ecological-biophysical criteria; ii) criteria were defined to establish the unit of analysis and the land cover classification of the defined area at 1:25,000 scale; and iii) the assessment of ES was made based on a consultation with experts from academic, administrative and scientific institutions about the capacity to supply and demand ES present in the land covers that make up the SES. It was found that the metropolitan ecological structure is composed of ten natural and semi-natural land covers, which have the capacity to provide cultural ES (high level), regulation ES (high and medium levels) and supply ES (low level). In addition, as expected, the perception was validated that the flat area of the SES-which concentrates productive, economic and service activities-is clearly the demanding one, while the areas located in the periphery-i.e. piedmonts and the Eastern and Western mountain chains-are the suppliers. Finally, the results of this research once again demonstrate that, from the academic angle, there are novel ways to strengthen the processes of formulating guidelines for planning and environmental management of metropolitan SES, from the combination of spatial analysis and expert knowledge.
\end{abstract}

Palabras clave: estructura ecológica metropolitana, estructura metropolitana construida, sistema socioecológico, servicios ecosistémicos, Cali.

Key words: Metropolitan ecological structure, built metropolitan structure, socioecological system, ecosystem services, Cali.

Recibido: 13 de enero de 2019

Aceptado: 8 de mayo de 2019

*Correspondencia: E. Zapata-Caldas, Departamento de Geografía, Universidad del Valle, Calle 13 \# 100-00, Edificio 384, oficina 4002, Ciudad Universitaria Meléndez, Cali, Colombia.E-mail: emmanuel.zapata@correounivalle.edu.co.

\section{Introducción}

Las ciudades se construyen a partir de procesos sociales y materializan en sí mismas los deseos humanos (Harvey, 2008). La proximidad y contigüidad espaciales de las ciudades facilitan el acceso a localizaciones específicas y, por ende, a servicios y bienes de los entramados urbanos. Así pues, una ciudad entendida como el resultado de procesos sociales, expresa la expansión e intensificación de las acciones (Martínez-Toro, 2014, 2018). Parte de este proceso implica que las ciudades atraen a personas y actividades económicas que adquieren la calidad 
de consumidores o proveedores de materias y energía (Hughes, 1993; Rojas et al., 2005). Así, las ciudades pasan por fases en las cuales influencian la organización de los espacios contiguos y configuran áreas metropolitanas o metrópolis (Stephens y Wikstrom, 2000; Martínez-Toro y Buitrago-Bermúdez, 2011).

Un modo de interpretar este proceso de expansión e intensificación urbana -el cual se entiende en esta investigación como metropolización- es a partir del concepto de sistema socioecológico (SSE) (Holling, 2001; Cumming, 2011). Este concepto permite incorporar nuevos cuerpos de conocimiento que orientan la resolución de problemáticas ambientales contemporáneas, pues reconoce las dinámicas de sistemas adaptativos complejos (Folke, 2006). Por ejemplo, Salas-Zapata et al. (2012) consideran que las acciones humanas y naturales -constitutivas de los sistemas socioecológicos- se dan por doble vía: por un lado, las intervenciones y actividades de carácter cultural, político, social y económico producen cambios y transformaciones en los SSE; por otro, las dinámicas de los ecosistemas influencian la cultura, las relaciones de poder y las actividades económicas de los seres humanos, partiendo de la idea de que la realidad es un sistema complejo (Salas-Zapata et al., 2012). Mediante esta concepción, queda claro que los sistemas socioecológicos son orgánicos, dado que las acciones de cada parte tienen incidencia sobre las demás y sobre el todo.

En ese sentido, se entiende que la urbanización y la metropolización son procesos que plantean relaciones sociedad-naturaleza complejas y profundas (Rojas et al., 2005). Por lo tanto, en los planos filosófico y metodológico, se interpreta la realidad del SSE "área de influencia metropolitana de Cali" a partir de estructuras, entre las cuales se pueden identificar al menos dos: la estructura metropolitana construida y la estructura ecológica metropolitana. La primera corresponde aáreas construidas y equipamientos que poseen funciones claras y correspondientes al desempeño de las ciudades. También puede entenderse como la combinación compleja de soportes materiales (p. ej., equipamientos urbanos, redes viales, zonas industriales materiales, etc.) concentrados en la ciudad y su entorno inmediato, cuya configuración está determinada por las relaciones y procesos de la organización social que están en permanente cambio (Marques y Pradilla, 2008). La segunda, conocida en Europa como infraestructura verde (EEA, 2011) ${ }^{1}$, fue definida inicialmente en el contexto colombiano ${ }^{2}$ por van der Hammen y Andrade (2003) como el "conjunto de ecosistemas naturales y seminaturales que tienen una localización, extensión, conexiones y estado de salud tales que garantiza el mantenimiento de la integridad de la biodiversidad, la provisión de servicios ambientales (agua, suelos, recursos biológicos y clima), como medida para garantizar la satisfacción de las necesidades básicas de los habitantes y la perpetuación de la vida". Por lo tanto, la estructura ecológica metropolitana es la encargada de proporcionar servicios ecosistémicos (SE) -entendidos como el aporte de los ecosistemas al bienestar de los seres humanos (Costanza et al., 1997; Helliwell, 1969; MA, 2005; Fisher, Turner et al., 2009) - a la estructura metropolitana construida.

1 "Red de áreas naturales y semi-naturales estratégicamente planeadas junto con otras características ambientales diseñadas y administradas para ofrecer un amplio rango de servicios ecosistémicos. Incorpora espacios verdes (así como ecosistemas acuáticos) y otras características físicas en áreas terrestres y marinas. En áreas terrestres, la infraestructura verde está presente en contextos rurales y urbanos" (EEA, 2011).

2 Para un mapa del país a escala 1.500.000. 
No obstante, en esta investigación se definió la estructura ecológica metropolitana usando las "coberturas de la tierra" ${ }^{3}$ como unidad de análisis. Las razones para ello fueron dos. La primera, que el concepto de cobertura de la tierra es ampliamente usado en distintos ejercicios de valoración de SE y en la creación de balances ecosistémicos (Burkhard et al., 2009; Koschke et al., 2012; Burkhard et al., 2014; Nedkov et al., 2015). De ahí que se facilitara la instrumentalización de la metodología en el SSE “área de influencia metropolitana de Cali”. Y, la segunda, que como resultado del uso de herramientas de percepción remota, las coberturas de la tierra pueden ser identificadas en tiempos relativamente cortos (en comparación con otras metodologías ${ }^{4}$ ) permitiendo así la observación de elementos reales de la superficie terrestre. En otras palabras, esta unidad de análisis permite observar claramente, y para un periodo dado, hechos naturales, seminaturales y antrópicos, así como su configuración espacial -localización, orientación, extensión y distribución(Gulinck et al., 2001).

Ademas, las coberturas de la tierra, a diferencia de los ecosistemas -entendidos desde una mirada biológica- permiten identificar de manera integral -i. e. teniendo en cuenta factores urbano-funcionales y ecológicos- los elementos del SSE e interpretar de manera más precisa el vínculo entre SE, estructura ecológica metropolitana y estructura metropolitana construida (Fig. 1).

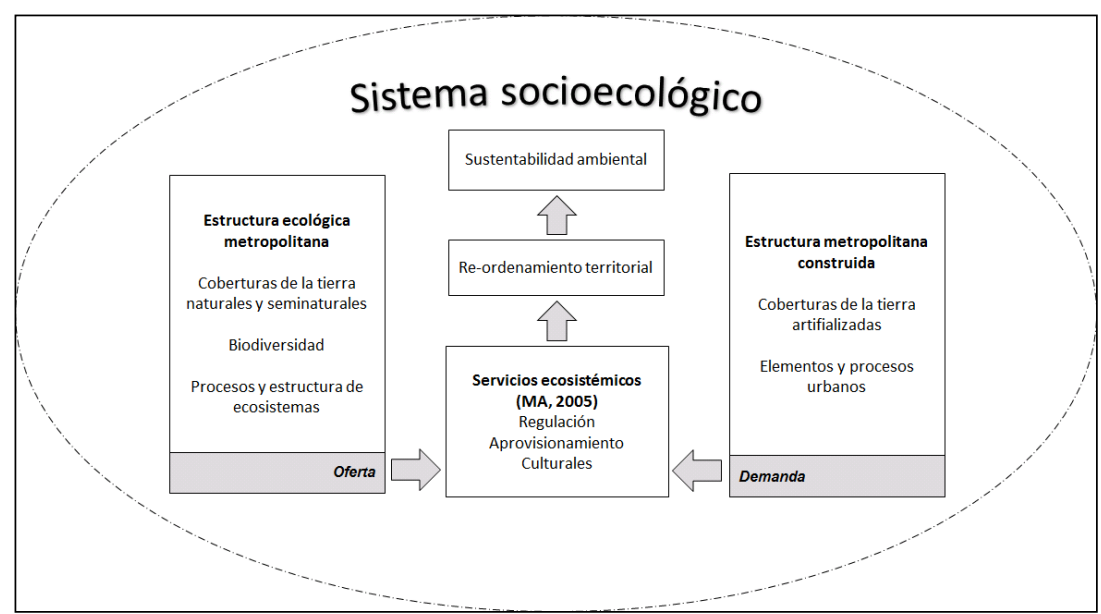

Figura 1. Vínculo entre estructuras y elementos articuladores del SSE metropolitano de Cali. Fuente: elaboración propia a partir de Burkhard et al. (2012).

3 El término "cobertura de la tierra" también suele denominarse "cobertura del suelo" en el contexto europeo.

4 Por ejemplo, valorar SE a partir "ecosistemas" implica definir parcelas de monitoreo para establecer índices y posteriormente extrapolarlos al área total del ecosistema en cuestión, limitando así el alcance de la valoración a un número reducido de SE identificados en la parcela, y principalmente los referidos a la acumulación y los flujos de biomasa o agua. 
Por consiguiente, dadas las circunstancias particulares del presente estudio, se decidió definir estructura ecológica metropolitana como "las coberturas de la tierra naturales y seminaturales que, por sus características ecológicas, tienen mayor capacidad para proporcionar SE al conjunto de formas de vida que componen un SSE determinado" (Tabares-Mosquera y Gaitán-Idárraga, 2018).

En términos instrumentales, este ejercicio de investigación propone establecer un SSE compuesto por la estructura ecológica metropolitana y la estructura metropolitana construida, que a su vez se relacionan a través de los SE (Fig. 1). En este contexto, los SE son idóneos para vincular los subsistemas ecológico y social, divididos históricamente en la ciencia tradicional (Jacobs et al., 2015).

Por otra parte, la biodiversidad y los procesos de los ecosistemas tienen un rol preponderante al interior de la estructura ecológica metropolitana, pues la biodiversidad -como característica central de los ecosistemas- es un aspecto fundamental para los procesos ecosistémicos que soportan la generación de los SE (Haines-Young y Potschin-Young, 2013; Potschin y Haines-Young, 2017). Por otro lado, el beneficio (in)directo humano de la oferta potencial de SE está condicionado por los modelos de ordenamiento territorial (OT), entendidos como la disposición de actividades y usos de la tierra. Tales actividades y usos constituyen parte de la "vida funcional" de la estructura metropolitana construida, que, al igual que la población, demanda SE para su funcionamiento y bienestar. Esta demanda de SE representa la presión social dentro del sistema sobre las coberturas de la tierra observables en la superficie -elementos naturales que cumplen funciones y procesos ecológicos más tarde concebidos por los seres humanos como SE (Costanza et al., 1997), o elementos seminaturales que reflejan la inscripción de la cultura en la superficie terrestre-.

De otra parte, en la Figura 1 se plantea la idea de sustentabilidad ambiental, resaltando el papel que tiene el OT como la reproducción espacial de los deseos e intereses de diversos agentes sociales. El concepto de sustentabilidad ambiental puede abordarse desde diferentes puntos de vista. Por un lado, puede verse como la búsqueda por mejorar el bienestar humano a través de la protección de las fuentes de materias primas utilizadas para satisfacer las necesidades humanas, a la vez que se asegura que los sumideros de desechos humanos no exceden su capacidad (Goodland, 1995). De esta manera, se previenen impactos sobre la sociedad y los ecosistemas. Por otra parte, desde la ecología se entiende la sustentabilidad como "la capacidad de un sistema de mantener constante su estado en el tiempo" (Gligo, 1995). Esta es una característica que se alcanza de manera espontánea en la naturaleza, pero es insuficiente al analizar un sistema socioecológico, ya que la intervención del ser humano crea situaciones artificiales. Según Gligo (1995), la sustentabilidad ambiental es la que conviene analizar, pues aborda la dimensión económica y social, incluyendo las estrategias de ordenamiento, desarrollo y ocupación de la superficie terrestre [ecosistemas]. En este orden de ideas, interpretar el sistema metropolitano como un todo interrelacionado requiere considerar un enfoque de sustentabilidad ambiental y no solo económico o social (Goodland, 1995). Allí es donde entran y son claves los SE. 
En línea con lo anterior, ¿qué se entiende por oferta y demanda de SE? Mientras que la oferta de SE hace referencia a "la capacidad de un área particular de proveer un conjunto de bienes y servicios de los ecosistemas" (Burkhard et al., 2012), la demanda de SE es la "sumatoria de todos los bienes y servicios ecosistémicos requeridos por un área particular" (Burkhard et al., 2012). Debe destacarse que la oferta y demanda de SE están conectadas inseparablemente porque "el estado de un SE está influenciado no solo por su suministro, sino también por las necesidades humanas y el nivel deseado de aprovisionamiento del SE por la sociedad" (Burkhard et al., 2012). Así, por ejemplo, fuera de los límites inmediatos de una ciudad, las demandas de su población urbana conducen a una serie de impactos que se expresan en la periferia. La necesidad insaciable de agua, alimentos, materiales de construcción y minerales por parte de una economía capitalista urbana conlleva una explotación de amplio alcance de los ecosistemas. Por este motivo, la demanda y la oferta de SE son una pieza fundamental al momento de proponer la estructura ecológica metropolitana. Tener una perspectiva de SSE aporta elementos sólidos y novedosos para contribuir a la planificación integral de áreas metropolitanas. En Colombia, tal proceso ha tenido un sesgo utilitarista, trayendo como consecuencia la fragmentación de ecosistemas.

Es importante resaltar que, aunque Cali no cuenta con un área metropolitana establecida jurídicamente, en la práctica su proceso de metropolización ha sido evidente dada la cantidad de servicios (p. ej. centros de comercio y equipamientos de salud, educación, recreación e investigación científica, etc.) y funciones ofrecidos a los diferentes municipios del sur del departamento del Valle del Cauca y norte del departamento del Cauca (Martínez-Toro y Buitrago-Bermúdez, 2011; Martínez-Toro y Patiño-Gómez, 2015).

Bajo este contexto, la planificación territorial como política pública espacial está en capacidad de establecer lineamientos que procuren la sustentabilidad ambiental con base en ejercicios que resalten la importancia de los servicios ecosistémicos en los procesos de planificación (Kaczorowska et al., 2016; Woodruff y Bendor, 2016; Cortinovis y Geneletti, 2018). Definitivamente, el conocimiento del SSE “área de influencia metropolitana de Cali", entendido como el conjunto de relaciones entre la estructura ecológica metropolitana y estructura metropolitana construida, aporta elementos para la planificación territorial orientada a la protección y conservación ambiental.

\section{Materiales y métodos}

La presente metodología para establecer la estructura ecológica del SSE "área de influencia metropolitana de Cali" se fundamenta en la identificación de aquellas coberturas de la tierra que proporcionan ampliamente SE a la estructura metropolitana construida, para lo cual se optó por el uso de métodos de investigación mixtos. El procedimiento contó con tres etapas importantes: i) delimitación del área del SSE, ii) establecimiento de la unidad de análisis (coberturas de la tierra), y iii) valoración de oferta y demanda de SE. 


\subsection{Delimitación del área del SSE}

Definir los límites de un SSE vinculado a un proceso de metropolización tiene varias implicaciones. Por un lado, requiere desprenderse de la rigidez establecida por los límites políticos y administrativos tradicionalmente usados para la gestión pública (i. e. municipales y departamentales, en el caso colombiano) y, por el otro, demanda una visión amplia y sistémica para planificar la realidad ecológica de un área determinada. En este caso particular, se consideraron tres criterios que, al ser aplicados en conjunto, permitieron definir el límite del SSE.

El primero fue un criterio urbano-funcional, con cuya aplicación se identificó la estructura metropolitana construida. En términos prácticos, se estableció la tercera corona metropolitana definida por Martínez-Toro y Patiño-Gómez (2015) como criterio para identificar los elementos urbanos (p. ej. cabeceras municipales, equipamientos colectivos, redes viales y ferroviarias, etc.) que conforman la estructura metropolitana construida.

El segundo criterio fue la selección de las cuencas hidrográficas que ofrecen agua a las áreas urbanas de los municipios vinculados a la tercera corona metropolitana. Tal como lo indican Nedkov et al. (2015), las cuencas hidrográficas "proporcionan la escala espacial apropiada para las evaluaciones de servicios [ecosistémicos] debido a que varias funciones de los ecosistemas relacionadas con el ciclo del agua se llevan a cabo dentro de sus límites". En este caso, las cuencas hidrográficas son las proveedoras de SE a la estructura metropolitana construida. Por tanto, los SE relacionados con el agua -suministro de agua dulce, purificación del agua, control de inundaciones, etc.- se basan en las funciones de los ecosistemas y los procesos desarrollados a escala de cuenca hidrográfica y operan como elementos articuladores del SEE (Fig. 1).

En cuanto al tercer criterio, considerando que algunas áreas de las cuencas seleccionadas bajo los criterios anteriores no están directamente relacionadas con la tercera corona metropolitana -como por ejemplo la cuenca baja del río Dagua, la cual vierte hacia el Océano Pacífico- se hizo un ajuste basado en la curva de nivel mínima a partir de la cual se localizan los elementos de la estructura metropolitana construida. Esta curva correspondió a $800 \mathrm{~m}$ s.n.m. (cálculo a partir de datos la NASA Jet Propulsion Laboratory [2009]).

De igual manera, al sur del SSE se hizo un ajuste del límite excluyendo el área de la cuenca del río Piendamó ${ }^{5}$-aguas arriba del punto donde inicia el embalse de La Salvajina-. El embalse fue construido para regular los desbordamientos del río Cauca en su planicie aluvial, donde principalmente se asienta la estructura metropolitana construida.

\footnotetext{
5 Área que no tiene conexión directa con la tercera corona metropolitana de Cali.
} 


\subsection{Establecimiento de la unidad de análisis y clasificación de coberturas de la tierra}

Para la selección de las coberturas se definieron dos criterios: i) la escala espacial de trabajo apropiada para el análisis supramunicipal en el SEE -asociada a la unidad mínima cartografiable (UMC) - y ii) el establecimiento de una leyenda de coberturas de la tierra para dicho sistema.

Respecto al primer criterio, teniendo en cuenta que la escala espacial de trabajo para la planeación detallada en Colombia es 1:5000 (Instituto Geográfico Agustín Codazzi [IGAC], 2018) y que el SSE debe analizarse desde la perspectiva supramunicipal, se concluyó que la escala 1:25.000 era apropiada para las dimensiones de este estudio. De acuerdo con Salitchev (2009) la UMC recomendada es una hectárea $\left(10.000 \mathrm{~m}^{2}\right)$.

En cuanto al segundo criterio, con el objetivo de identificar los elementos de la estructura ecológica metropolitana y estructura metropolitana construida a escala 1:25.000, se trabajó a partir de la leyenda Coordination of Information on the Environment (CORINE) Land Cover adaptada para Colombia (IDEAM, 2010). Para el caso de estudio se seleccionaron las categorías tres y cuatro ${ }^{6}$ de la leyenda, debido a que permiten observar elementos con niveles de precisión medios a altos -en otras palabras, fenómenos supramunicipales-. En este orden de ideas, se obtuvo una leyenda de 28 coberturas de la tierra en el SSE. Para identificar las coberturas, se utilizaron imágenes satelitales de la constelación RapidEye, cuya resolución espacial es de $5 \mathrm{~m}$ por píxel, y se conformó un mosaico con imágenes correspondientes al periodo 2013-2016.

Una vez aplicados los criterios, se realizó la clasificación de coberturas usando el algoritmo Random Trees (ESRI, 2017; Şatır y Berberoğlu, 2012). Dicho ejercicio obedeció a dos factores: primero, la información oficial de coberturas de la tierra se generó a una escala espacial poco detallada a nivel nacional (1:100.000) (IDEAM, 2010) y para contextos supramunicipales (1:25.000); y, segundo, los datos espaciales de coberturas de la tierra desarrollados a escala 1:25.000 por las autoridades ambientales con jurisdicción en el $\mathrm{SSE}^{7}$ no estaban actualizados para el año 2016 -por ejemplo, los datos espaciales de la Corporación Autónoma Regional del Valle del Cauca (CVC) solo cubren el rango de años 1996 a 2010-.

6 Para el nivel cuatro se seleccionó únicamente la cobertura de caña de azúcar. Esto se hizo teniendo en cuenta la facilidad para identificarla con el uso de imágenes satelitales de resolución media, dada su gran extensión en la parte plana del SSE. Otros tipos de cultivos no son fácilmente identificables con esta clase de imágenes, a menos que se realice trabajo de campo como instrumento de validación del levantamiento de coberturas de la tierra.

7 Corporación Autónoma Regional del Valle del Cauca y Corporación Autónoma Regional del Cauca. 


\subsection{Valoración de oferta y demanda de SE}

Para la valoración de la oferta y demanda de SE, se tuvo en cuenta la tipología Common International Classification of Ecosystem Services (CICES) v4.3 (HainesYoung y Potschin-Young, 2013, 2017). Se escogió esta clasificación debido a que garantiza retener la conexión con las funciones ecosistémicas y los procesos con estructuras naturales que contribuyen al bienestar humano, considerando los SE finales. Estos servicios se clasifican en tres categorías: de aprovisionamiento, de regulación y culturales. Una vez definidos los SE, se realizó la selección de expertos que valoraron su oferta y demanda (Jacobs y Burkhard, 2017; Kaczorowska et al., 2018). Se dividió a los expertos en cuatro grupos temáticos: áreas de producción agrícola, bosques y áreas seminaturales, áreas húmedas -para valoración de la oferta- y áreas artificializadas -para valoración de la demanda-. En cuanto a la selección de los expertos, se definieron los siguientes criterios: i) ser especialistas en al menos uno de los grupos; ii) ser conocedores del área del SSE; y iii) estar afiliados a instituciones públicas administrativas (alcaldías y gobernaciones), universidades y centros privados de investigación. Por lo tanto, el perfil incluyó profesionales de ciencias naturales aplicadas, humanidades, ingeniería y socioeconomía.

Para facilitar la participación de los expertos, se creó un formulario por cada grupo temático en la plataforma gratuita de Google Docs (Google, 2017) (Fig. 2). Un ejemplo es el formulario de "áreas de producción agrícola". El formulario permitió recopilar las respuestas de los expertos de manera sistemática y ordenada en hojas de cálculo. Además, como parte de la información de soporte de la consulta, se incluyó un enlace al mapa de coberturas de la tierra del área del SSE, el cual se hospedó en la plataforma de ArcGIS Online; un enlace a la descripción de los servicios ecosistémicos (adaptado de Haines-Young y Potschin, 2013); un enlace a la descripción de las coberturas de la tierra asociadas a cada grupo temático; y un enlace al glosario de términos usados en la investigación.

La Figura 2 presenta el contenido del formulario en su página introductoria (izquierda), el mapa de coberturas de la tierra (derecha) y un ejemplo de una de las secciones de preguntas sobre SE de aprovisionamiento (abajo) (ver sección de anexos para conocer todas las preguntas).

Para la valoración de los SE de cada cobertura por parte de los expertos asociados a un determinado grupo temático, se usó la escala Likert que se registra en la Tabla 1 (Clason y Dormody, 1994; Boone y Boone, 2012; Koschke et al., 2012; Jacobs et al., 2015; Albert et al., 2016). Vale la pena resaltar que la clase cero (no relevante) indica que existe una oferta o demanda "insignificante" del SE. En ese sentido, la categoría "muy bajo" apunta a una capacidad "significativa pero mínima” de un SE. Un ejemplo del uso de las dos categorías puede observarse en Jacobs et al. (2015). Naturalmente, existe una gran dependencia de la experiencia, el conocimiento y la objetividad del experto para valorar si la oferta y la demanda de SE es relevante o no. 
El formulario de consulta a expertos sobre servicios ecosistémicos en el área de influencia metropolitana de Santiago de Cali consta de tres secciones: 1) introducción; 2) mapa de coberturas; 3) preguntas de consulta. En la introducción se indica: "Debido a la concentración de actividades económicas, sociales y políticas, Santiago de Cali determina aspectos morfológico-funcionales de los municipios vecinos, consolidando lo que se distingue como un área de influencia metropolitana, la cual no ha sido establecida jurídicamente, dificultando a su vez el reconocimiento del tema ambiental como hecho supramunicipal. Este panorama evidencia la poca atención que se le ha prestado a la relación de dependencia que tiene la sociedad humana de los ecosistemas que mantienen la vida. De ahí, que exista un vacío en términos de instrumentos de planificación, ordenamiento y gestión a escala supramunicipal para el área de influencia metropolitana.

Para afrontar dicha problemática, esta investigación desarrolla una metodología mixta que se ejecuta en fases múltiples. En este momento nos encontramos en la etapa del establecimiento de la estructura ecológica metropolitana (EEM), en la cual, a partir de identificación de coberturas de la tierra consultaremos a personas expertas sobre la capacidad de las coberturas para proveer servicios ecosistémicos. Para efectos de la consulta, se seleccionaron expertos -considerando su conocimiento del tema y del área, su filiación institucional y su experiencia en planificación y gestión pública, entre otros criterios- para hacer parte de cuatro grupos temáticos según el conjunto de coberturas identificadas. Estos cuatro grupos son: i) áreas de producción agrícola, ii) bosques y áreas seminaturales, iii) áreas húmedas y superficies de agua y, por último, iv) áreas actualizadas. Mediante esta consulta, los expertos nos ayudarán a identificar la EMM a escala 1:25.000.

En su condición de experto(a) lo(a) invitamos a participar de este ejercicio diligenciando el presente formulario. Respetuosamente le recordamos que la recepción de sus respuestas tiene como plazo el día viernes, 29 de septiembre de 2017. Muchas gracias.
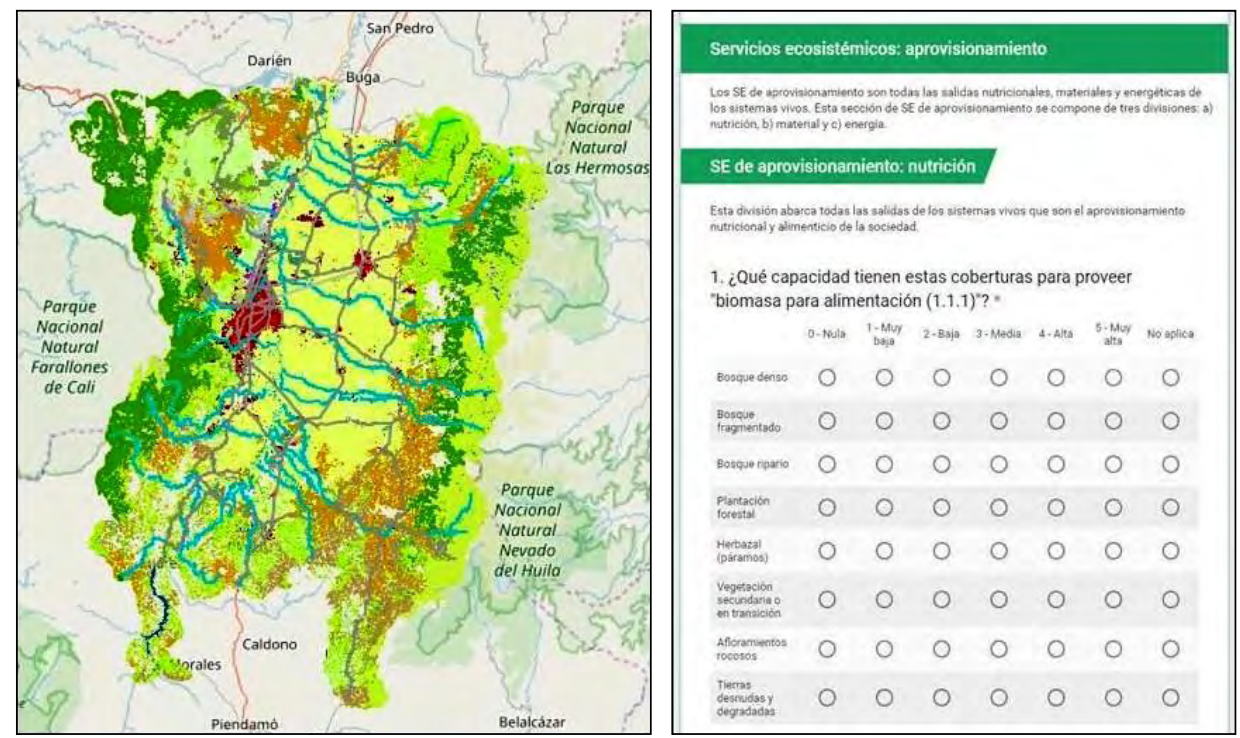

Figura 2. Secciones del formulario de consulta. Arriba: Introducción. Abajo: mapa de coberturas y ejemplo de preguntas de consulta. Fuente: elaboración propia. 
Tabla 1. Escala Likert ordinal de valoración de SE. Fuente: Jacobs et al. (2015).

\begin{tabular}{|l|c|}
\hline \multicolumn{1}{|c|}{ Valor cualitativo } & Valor cuantitativo \\
\hline No relevante & 0 \\
\hline Muy bajo & 1 \\
\hline Bajo & 2 \\
\hline Medio & 3 \\
\hline Alto & 4 \\
\hline Muy alto & 5 \\
\hline
\end{tabular}

En cuanto al contenido de la consulta dirigida a expertos, la valoración de SE fue desarrollada a partir de dos tipos de formularios: uno de oferta y otro de demanda (Tabla 2). La consulta se realizó de manera estructurada, reproduciendo la configuración jerárquica de CICES y relacionando cada SE con una cobertura de la tierra.

Tabla 2. Características generales de la consulta a expertos. Fuente: elaboración propia.

\begin{tabular}{|c|c|c|c|}
\hline $\begin{array}{c}\text { Formu- } \\
\text { lario }\end{array}$ & Pregunta clave & Intención de la pregunta & $\begin{array}{c}\text { Coberturas valoradas por } \\
\text { formulario }\end{array}$ \\
\hline \multirow{3}{*}{$\begin{array}{l}\text { Oferta de } \\
\text { SE }\end{array}$} & \multirow{3}{*}{$\begin{array}{l}\text { ¿Qué capacidad tienen } \\
\text { estas coberturas para } \\
\text { proporcionar "SE"? }\end{array}$} & \multirow{3}{*}{$\begin{array}{l}\text { Valorar la capacidad } \\
\text { de cada cobertura de la } \\
\text { tierra para ofertar un SE } \\
\text { particular }\end{array}$} & $\begin{array}{l}7 \text { coberturas -áreas de producción } \\
\text { agrícola- }\end{array}$ \\
\hline & & & $\begin{array}{l}10 \text { coberturas }-(8) \text { bosques y áreas } \\
\text { seminaturales, (1) instalaciones } \\
\text { recreativas* y (1) zonas verdes } \\
\text { urbanas*_ }\end{array}$ \\
\hline & & & $\begin{array}{l}4 \text { coberturas -áreas húmedas y } \\
\text { superficies de agua- }\end{array}$ \\
\hline $\begin{array}{l}\text { Demanda } \\
\text { de SE }\end{array}$ & $\begin{array}{l}\text { ¿Cuál es el nivel de } \\
\text { demanda de "SE" de estas } \\
\text { coberturas de la tierra? }\end{array}$ & $\begin{array}{l}\text { Puntuar el nivel de de- } \\
\text { manda de todos los bienes } \\
\text { y SE requeridos por cada } \\
\text { cobertura de la tierra }\end{array}$ & $\begin{array}{l}18 \text { coberturas -(9) áreas artificial- } \\
\text { izadas, (7) áreas de producción } \\
\text { agrícolas, (1) plantación forestal y } \\
\text { (1) cuerpos de agua artificiales**- }\end{array}$ \\
\hline
\end{tabular}

* Coberturas seminaturales adicionadas que ofertan SE y contribuyen al bienestar humano.

** Se consultaron todas las coberturas de la leyenda que demandan SE.

Posteriormente, las respuestas de los expertos fueron promediadas para obtener las matrices de oferta y demanda de SE en la escala Likert. Con ese resultado, y con base en las recomendaciones expuestas por Burkhard et al., (2009, 2014), se establecieron cuatro criterios para identificar las coberturas de la tierra que componen la estructura ecológica metropolitana: i) multifuncionalidad o capacidad de una cobertura para proporcionar un gran número de SE; ii) singularidad o aptitud de una cobertura para ofrecer SE únicos; iii) capacidad ecosistémica que obtiene una cobertura al calcular su balance entre la oferta y la demanda de SE; y iv) importancia relativa que corresponde a la valoración de una cobertura por expertos para identificar aquellas que proporcionan los SE más significativos para una población (Tabla 3). Los criterios de multifuncionalidad, capacidad ecosistémica e importancia relativa operan de forma semejante: a mayor 
número, mejor valoración para cada criterio. Por el contrario, el criterio de singularidad es inverso: a menor número, mayor valoración.

Tabla 3. Criterios para establecer la estructura ecológica metropolitana. Fuente: elaboración propia

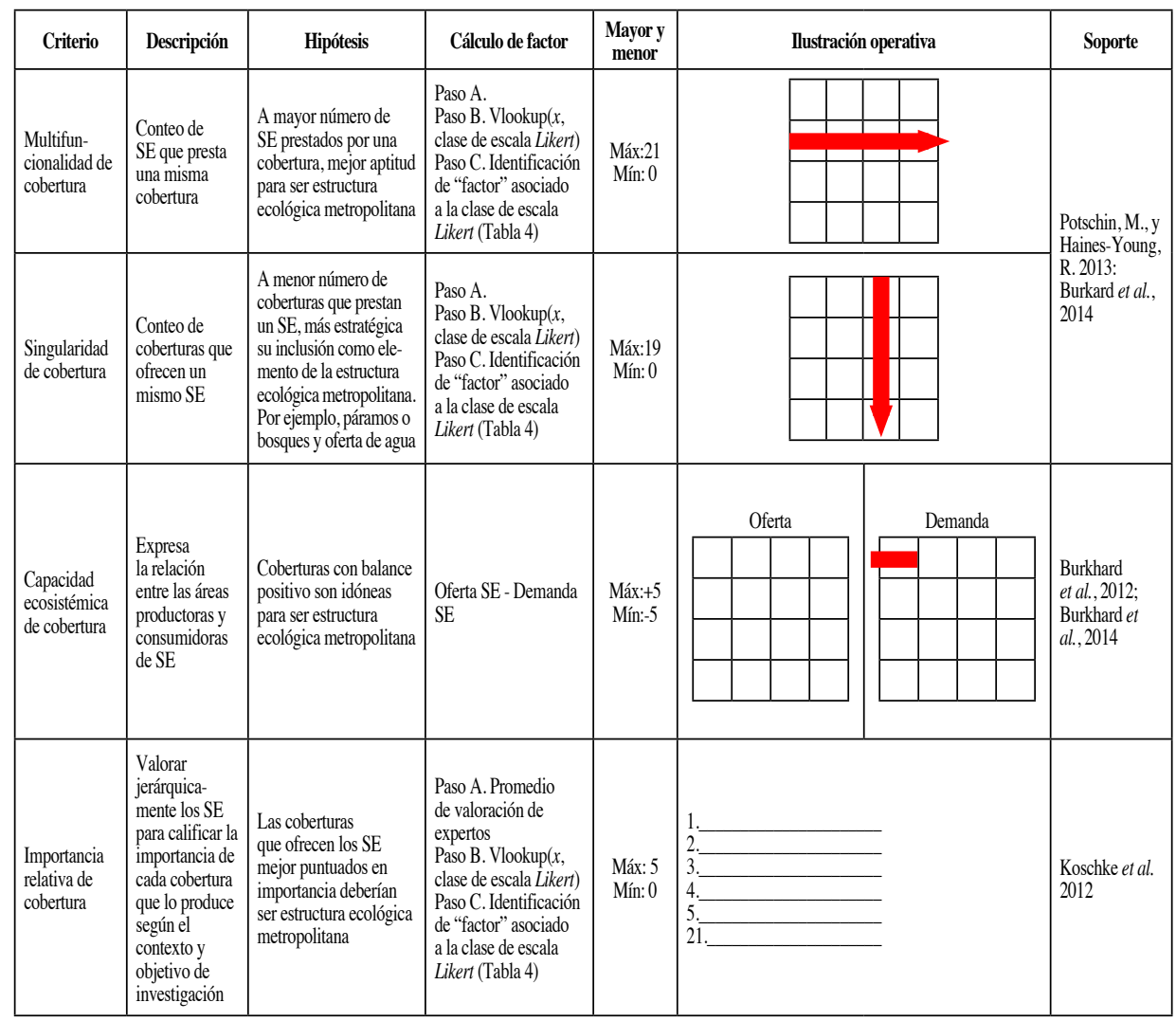

La propuesta e instrumentalización de estos criterios enriquece los alcances de la matriz de oferta y demanda de SE mediante la comparación cruzada de los valores estimados "verticalmente, dentro de las categorías [de SE] y en diferentes unidades espaciales [y] horizontalmente, dentro de unidades espaciales [coberturas de la tierra] individuales en diferentes [SE]" (Potschin y Haines-Young, 2013; Burkhard et al., 2014). Adicionalmente, las comparaciones entre los valores de la matriz deben normalizarse en las mismas unidades y escalas para que sean más comparables (Burkhard et al., 2014).

Para crear las matrices de los criterios se aplicó una estrategia de normalización usando la escala Likert con el fin de hacer el método más genérico, replicable y comparable con otros ejercicios (Burkhard et al., 2009, 2014; Koschke et al., 2012). Este procedimiento consistió en multiplicar cada entrada de la matriz de oferta por el factor asociado a la clase Likert de la Tabla 4 (Fig. 3) (Stanford University, 2017). 
Tabla 4. Normalización de datos por criterio. Fuente: elaboración propia.

\begin{tabular}{|c|c|c|c|c|}
\hline $\begin{array}{c}\text { Clase } \\
\text { Likert }\end{array}$ & Factor & $\begin{array}{c}\text { Multi- } \\
\text { fun-cional- } \\
\text { idad }\end{array}$ & $\begin{array}{c}\text { Importancia } \\
\text { relativa }\end{array}$ & $\begin{array}{c}\text { Capacidad } \\
\text { ecosistémica }\end{array}$ \\
\hline 0 & 0,17 & 3,5 & 0,8 & $-3,3$ \\
\hline 1 & 0,33 & 7,0 & 1,7 & $-1,7$ \\
\hline 2 & 0,50 & 10,5 & 2,5 & 0,0 \\
\hline 3 & 0,67 & 14,0 & 3,3 & 1,7 \\
\hline 4 & 0,83 & 17,5 & 4,2 & 3,3 \\
\hline 5 & 1,00 & 21,0 & 5,0 & 5,0 \\
\hline
\end{tabular}

\begin{tabular}{|c|c|c|}
\hline $\begin{array}{c}\text { Clase Likert } \\
\text { invertida }\end{array}$ & Singularidad & Factor invertido \\
\hline 5 & 3,2 & 1,00 \\
\hline 4 & 6,3 & 0,83 \\
\hline 3 & 9,5 & 0,67 \\
\hline 2 & 12,7 & 0,50 \\
\hline 1 & 15,8 & 0,33 \\
\hline 0 & 19,0 & 0,17 \\
\hline
\end{tabular}

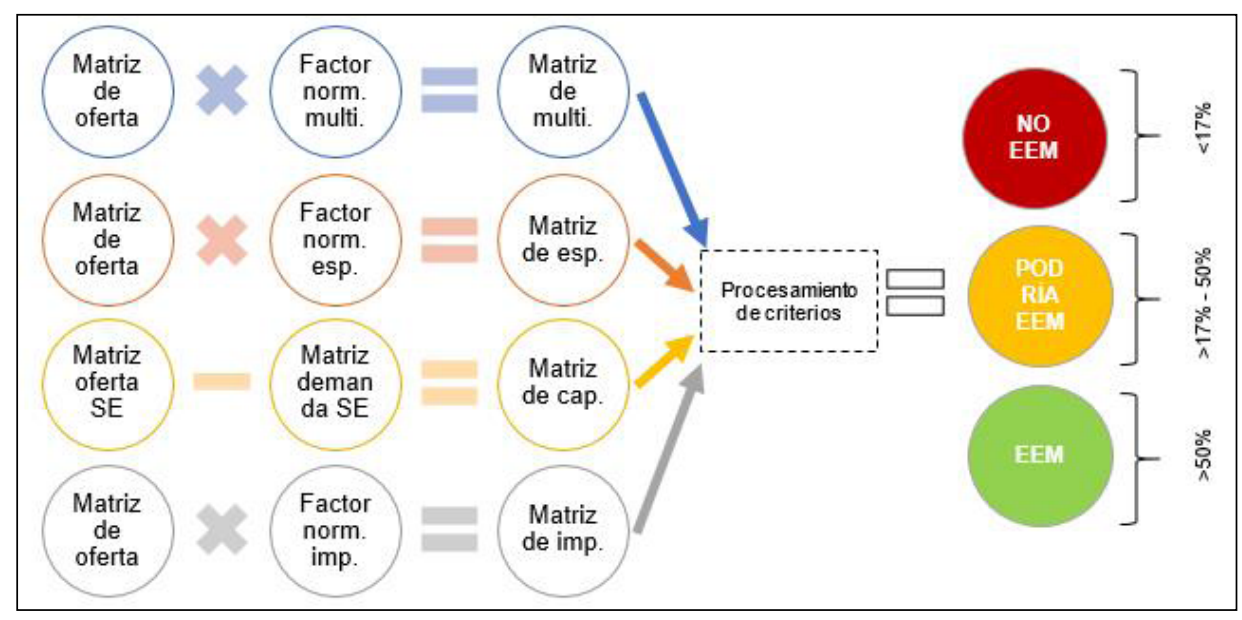

Figura 3. Esquema operativo del procesamiento de criterios para identificar la estructura ecológica metropolitana ${ }^{8}$. Fuente: elaboración propia.

Posteriormente, teniendo en cuenta la escala Likert y como lo indica la Tabla 5, se definió que las coberturas que hacen parte de la estructura ecológica metropolitana son aquellas clasificadas en "media (3)", "alta (4)" y "muy alta (5)" -en otras palabras, las coberturas cuyo resultado después del procesamiento de los cuatro criterios (i. e. sumatoria) se ubicaron por encima del 50\%-. En ese sentido, las coberturas que no son parte de la estructura ecológica metropolitana corresponden a aquellas cuyo resultado las ubicó en la categoría "sin relevancia (0)", es decir, entre el 0\% y el 17\%, y las que podrían serlo son las correspondientes a las categorías "muy bajo (1)" y "bajo (2)" entre el $17 \%$ y el $50 \%-($ Fig. 3).

8 La matriz de capacidad ecosistémica fue normalizada para que los valores de este criterio no fueran negativos y se ciñeran a la escala Likert de cero (0) a cinco (5). 
Tabla 5. Categorías resultantes de la operación de los cuatro criterios. Fuente: elaboración propia.

\begin{tabular}{|c|c|c|c|}
\hline$\%$ & \multicolumn{2}{|c|}{ Clase } & Resultado \\
\hline 17 & 0 & Sin relevancia & No es estructura ecológica metropolitana \\
\hline 33 & 1 & Muy bajo & \multirow{2}{*}{ Podría ser estructura ecológica metropolitana } \\
\hline 50 & 2 & Bajo & \\
\hline 67 & 3 & Medio & \\
\hline 83 & 4 & Alto & Es estructura ecológica metropolitana \\
\hline 100 & 5 & Muy alto & \\
\hline
\end{tabular}

\section{Resultados}

La aplicación de la metodología presentada anteriormente permitió establecer la estructura ecológica del SSE “área de influencia metropolitana de Cali”. En este sentido, la presente sección describe los resultados obtenidos para cada una de las fases metodológicas, a saber: i) delimitación del área del SSE, ii) identificación de las coberturas de la tierra y su definición como unidad de análisis espacial, y iii) valoración de la oferta y demanda de SE, a partir de la cual se estableció la estructura ecológica metropolitana.

\subsection{SSE "área de influencia metropolitana de Cali"}

La aplicación de los criterios citados en la metodología permitió obtener la delimitación del SSE “área de influencia metropolitana de Cali”. La Figura 4A muestra la delimitación de la tercera corona metropolitana (Martínez-Toro y PatiñoGómez, 2015) y los centros urbanos incluidos en ella, así como los equipamientos regionales (6), las unidades comerciales (18) y zonas industriales (5). La delimitación del SEE incorporó 30 cuencas hidrográficas, de las cuales 29 vierten al río Cauca y una (1) al Océano Pacífico. En términos de división político-administrativa, el área cubre 16 municipios del departamento del Valle del Cauca y 14 del departamento del Cauca (Fig. 4B). Con esta delimitación, la extensión total del SEE correspondió a $8138 \mathrm{~km}^{2}$, agrupando una población aproximada de 4.200 .000 habitantes (DANE, 2009).

En cuanto a los límites del SEE, al norte se encuentra la cuenca del río Yotoco, al suroccidente la del río Piendamó y, al sur oriente la del río Palo. Al oriente, su límite es la línea divisoria de aguas de la Cordillera Central y al occidente corresponde a la divisoria de aguas de la Cordillera Occidental (Fig. 4B). 

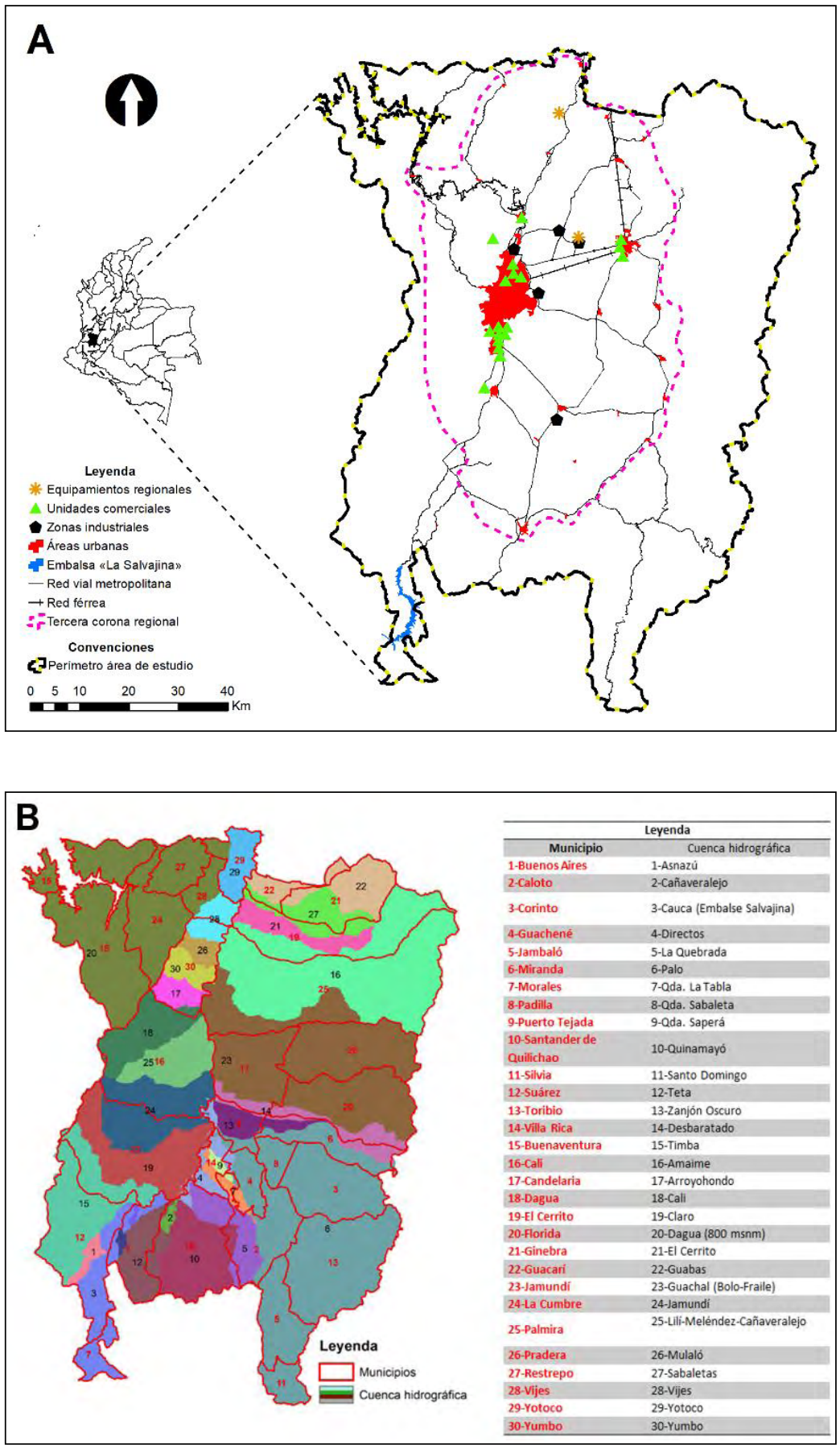

Figura 4. SSE "área de influencia metropolitana de Cali”. Fuente: elaboración propia. 


\subsection{Clasificación de coberturas de la tierra}

El mapa de coberturas del SEE "área de influencia metropolitana de Cali” a escala 1:25.000 se presenta en la Figura 5. De acuerdo con CORINE Land Cover adaptado para Colombia-leyenda de referencia-, el mapa está compuesto por 28 coberturas de la tierra, las cuales se agrupan en cinco categorías:

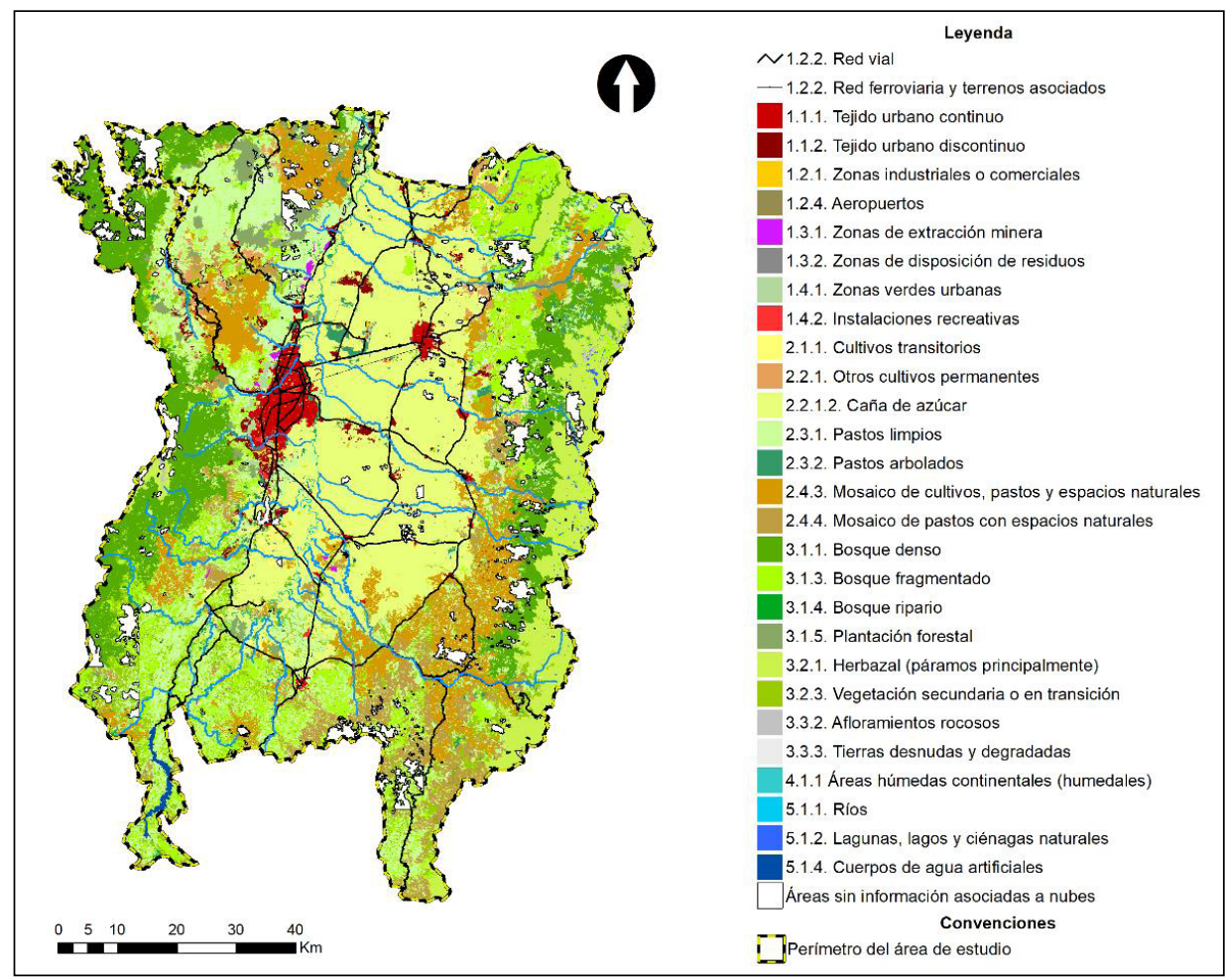

Figura 5. Mapa de coberturas de la tierra resultado de la clasificación de imágenes satelitales RapidEye. Fuente: elaboración propia de las imágenes de satélites RapidEye.

- Áreas artificializadas (9): aeropuertos; instalaciones recreativas; red vial, ferroviaria y terrenos asociados; tejido urbano continuo; tejido urbano discontinuo; zonas de disposición de residuos; zonas de extracción minera; zonas industriales o comerciales; zonas verdes urbanas.

- Áreas de producción agrícola (7): caña de azúcar; cultivos transitorios; mosaico de cultivos, pastos y espacios naturales; mosaico de pastos con espacios naturales; otros cultivos permanentes; pastos arbolados; pastos limpios.

- Bosques y áreas seminaturales (8): afloramientos rocosos; bosque denso; bosque fragmentado; bosque ripario (ribereño); herbazal (páramos); plantación forestal; tierras desnudas y degradadas; vegetación secundaria o en transición. 
- Áreas húmedas (1): áreas húmedas continentales (humedales).

- Superficies de agua (3): cuerpos de agua artificiales; lagunas, lagos y ciénagas naturales; ríos.

Una vez obtenido el mapa de coberturas de la tierra para el SEE “área de influencia metropolitana de Cali", se realizó la consulta a expertos en SE. El mapa fue uno de los principales insumos para la consulta, pues permitió identificar claramente la unidad de análisis a tener en cuenta para valorar los SE.

\subsection{Valoración de oferta y demanda de SE}

Además de las coberturas de la tierra mencionadas, otro insumo clave para esta metodología fue el catálogo de SE. Se escogió la clasificación CICES reportada en Haines-Young y Potschin-Young (2013), a partir de la cual se seleccionaron 21 SE que, a juicio de los investigadores, se ajustan apropiadamente a la escala espacial del fenómeno metropolitano de Cali. En este ejercicio, los expertos valoraron de forma virtual la oferta y la demanda de los 21 SE clasificados en aprovisionamiento, regulación y culturales. Los SE considerados fueron los siguientes:

- Aprovisionamiento (8): biomasa para nutrición; agua para nutrición; biomasa para material; agua como material; materiales abióticos metálicos y no metálicos; biomasa para energía; fuente abiótica renovable; fuente abiótica no renovable.

- Regulación y mantenimiento (9): mediación por sistemas vivos; flujos de masa; flujos de líquido; flujos de gases/aire; mantenimiento del ciclo de vida; hábitat y protección de reserva genética; control de plagas y enfermedades; formación y composición del suelo; mantenimiento de la composición química del agua y composición atmosférica; regulación del clima.

- Culturales (4): experiencia física; experiencia intelectual y representativa; experiencia espiritual y/o emblemática; existencia y valor intrínseco natural.

A través del formulario en línea, se procesaron 27 respuestas de diferentes expertos, las cuales, al ser analizadas, permitieron la identificación de las coberturas que proporcionan mayor cantidad de SE y aquellas que demandan mayor número de SE (Tabla 6). Las coberturas con mayor oferta de SE son bosque denso, bosque ribereño, herbazales, ríos y mosaico de pastos con espacios naturales. Los evaluadores dieron valoraciones altas al bosque denso y herbazales, coincidiendo con que son las coberturas naturales de mayor extensión en SSE. Las coberturas ríos y bosque ribereño obtuvieron destacada valoración. Los mosaicos de cultivos con espacios naturales merecen una mención especial por ser una cobertura seminatural que aporta SE.

La valoración realizada por los expertos indica que las tierras desnudas y degradadas, afloramientos rocosos, pastos limpios, cuerpos de agua artificializada e instalaciones recreativas son las coberturas que menos SE proporcionan. Este resultado llama la atención, ya que a juicio de los investigadores las coberturas de caña de azúcar y pastos limpios son las que aportan menos bienestar a los seres humanos. 
Tabla 6. Análisis de oferta y demanda de SE por coberturas de la tierra. Fuente: elaboración propia.

\begin{tabular}{|c|c|c|c|c|c|c|c|}
\hline \multicolumn{5}{|c|}{ Oferta } & \multicolumn{3}{c|}{ Demanda } \\
\hline Mayor valor & \multicolumn{2}{|c|}{ Menor valor } & \multicolumn{2}{c|}{ Mayor valor } & \multicolumn{2}{c|}{ Menor valor } \\
\hline Bosque denso & 4,3 & $\begin{array}{c}\text { Tierras } \\
\text { desnudas y } \\
\text { degradadas }\end{array}$ & 0,4 & $\begin{array}{c}\text { Tejido urbano } \\
\text { continuo }\end{array}$ & 4,1 & Pastos arbolados & 1,7 \\
\hline Herbazales & 3,6 & $\begin{array}{c}\text { Afloramiento } \\
\text { rocoso }\end{array}$ & 1,4 & $\begin{array}{c}\text { Tejido urbano } \\
\text { discontinuo }\end{array}$ & 4,0 & Pastos limpios & 1,8 \\
\hline Bosque ribereño & 3,4 & Pastos limpios & 1,4 & $\begin{array}{c}\text { Zonas } \\
\text { industriales y } \\
\text { comerciales }\end{array}$ & 3,7 & $\begin{array}{c}\text { Mosaico de pastos } \\
\text { con espacios } \\
\text { naturales }\end{array}$ & 1,8 \\
\hline $\begin{array}{c}\text { Mosaico de } \\
\text { cultivos con es- } \\
\text { pacios naturales }\end{array}$ & 3,3 & $\begin{array}{c}\text { Instalaciones } \\
\text { recreativas }\end{array}$ & 2,0 & $\begin{array}{c}\text { Instalaciones } \\
\text { recreativas }\end{array}$ & 2,8 & $\begin{array}{c}\text { Mosaico de cultivos } \\
\text { con espacios } \\
\text { naturales }\end{array}$ & 1,9 \\
\hline
\end{tabular}

Por otro lado, de acuerdo con la consulta, las coberturas de la tierra que más SE demandan son tejido urbano continuo, tejido urbano discontinuo, zonas industriales y comerciales, aeropuertos e instalaciones recreativas. Esto concuerda con la localización en donde son requeridos y consumidos los SE, lo cual resalta la dependencia que tienen los asentamientos urbanos, de mayor o menor escala, de los elementos naturales. De este conjunto de coberturas, Cali y sus vecinos más próximos conforman la mancha urbana más extensa y que congrega la mayor cantidad de población en el área y, por consiguiente, la que genera mayor presión en los ecosistemas para producir SE.

Finalmente, las coberturas de la tierra que menos demandan SE son los pastos arbolados, pastos limpios, mosaico de pastos con espacios naturales, mosaico de cultivos con espacios naturales y plantación forestal.

\subsubsection{Aplicación de los criterios de identificación de la estructura ecológica metropolitana}

Las matrices de oferta y demanda de SE creadas a partir de la consulta a expertos fueron la base para calcular y aplicar los cuatro criterios que permitieron identificar los elementos de la estructura ecológica metropolitana. La Figura 6 muestra la distribución espacial del resultado de la aplicación de criterios por cada cobertura de la tierra.

De la Figura 6 se concluye que, mientras la periferia del SSE tuvo valoraciones altas en los criterios (valores 4 y 5), el centro comprende los valores más bajos (valores 0,1 y 2) -situación relacionada directamente a la localización de las coberturas-. Por otro lado, mientras que las coberturas más naturales -bosque denso, herbazales, mosaico de cultivos con espacios naturales- se localizan en el perímetro del área, es decir, los piedemontes y partes altas de las cordilleras Central y Occidental, las seminaturales y artificializadas -tejido urbano, zona industrial, aeropuertos, etc.- están en el centro del SSE, en la zona plana. 


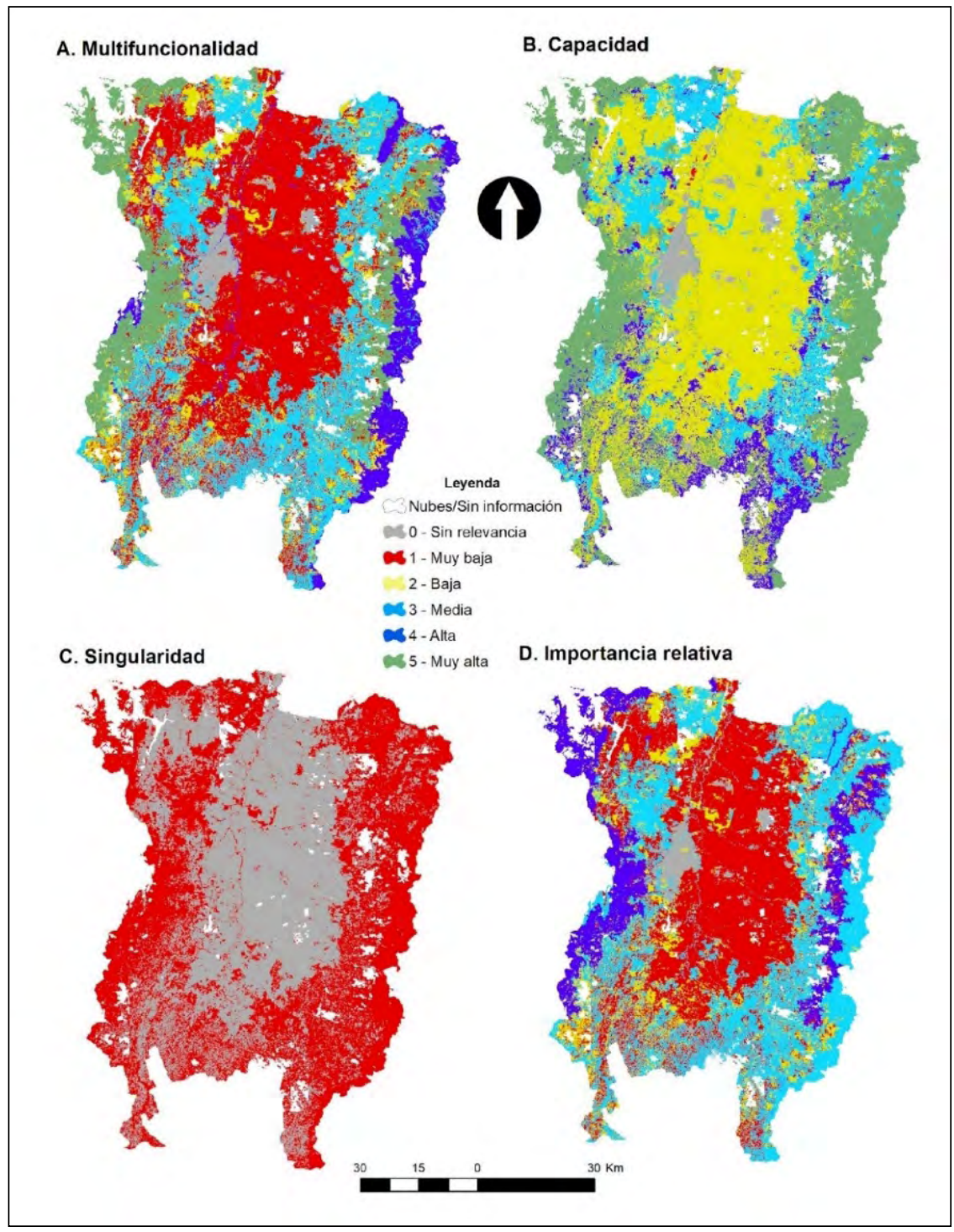

Figura 6. Espacialización de los criterios de identificación de estructura ecológica metropolitana. A) Multifuncionalidad, B) capacidad, C) singularidad y D) importancia relativa. Fuente: elaboración propia.

El criterio de capacidad ecosistémica fue el más representado, ya que comprendió el rango total de las clases definidas (de 0, sin relevancia, a 5, muy alto). La multifuncionalidad fue el segundo criterio más representado, con un rango cero 0 (sin relevancia) a 4 (alto). Le siguió el criterio de importancia relativa, cuyo rango se ubicó entre las clases 0 (sin relevancia) y 3 (medio). Por último, el criterio 
menos representado fue la singularidad, con un rango entre 0 (sin relevancia) y 2 (bajo). De acuerdo con estos resultados, queda claro que el área plana del SSE concentra actividades productivas, poder económico y servicios, y que la periferia soporta la existencia de la vida de todas las especies que habitan esta área y sus actividades.

Teniendo en cuenta estos criterios, se identificaron las coberturas de la tierra que más aportan SE y que, por lo tanto, son parte de la estructura ecológica metropolitana; adicionalmente, se clasificaron aquellas que podían serlo y otras que definitivamente no. Se consideró arbitrario usar una clasificación binaria al tratarse de elementos artificiales, seminaturales y naturales, cada uno con diferentes grados de intervención. En la Figura 7 se observa que la estructura ecológica metropolitana asume un patrón espacial en forma de anillo o corona ecológica y abarca $3586 \mathrm{~km}^{2}$, lo que corresponde al $44 \%$ del área total. Las coberturas que podría ser estructura ecológica metropolitana están localizadas en un anillo intermedio más extenso y tienen un área de $4294 \mathrm{~km}^{2}$, correspondiendo al $53 \%$ del área del SSE. Las coberturas que hacen parte de la clase no es estructura ecológica metropolitana están dispuestas en el núcleo y ocupan $259 \mathrm{~km}^{2}$, es decir el $3 \%$ del área del SSE.

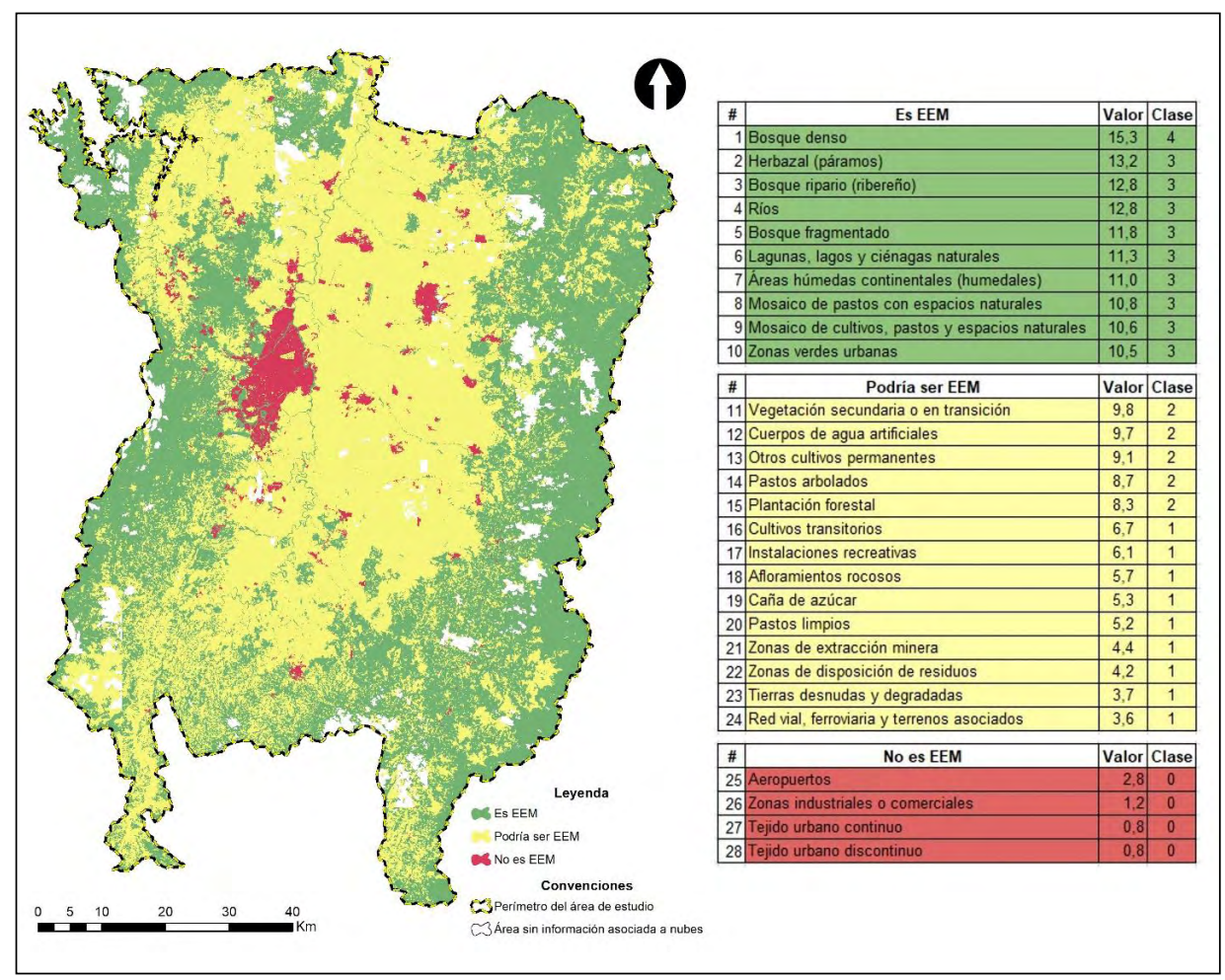

Figura 7. Espacialización de los resultados de la operación de los cuatro criterios. Fuente: elaboración propia. 
Las coberturas que fueron identificadas como no es estructura ecológica metropolitana son: aeropuertos $(2,8)$; zonas industriales y comerciales $(1,2)$; tejido urbano continuo $(0,8)$; y tejido urbano discontinuo $(0,8)$. Todas se clasificaron como clase 0 (sin relevancia), pues el resultado de su valoración integral estuvo por debajo del $17 \%$. Estas coberturas, más que contribuir, son las encargadas de demandar SE, pues representan actividades económicas asociadas al proceso de metropolización (Fig. 7). Llama especialmente la atención que las áreas urbanas, dispuestas de forma continua o discontinua, contabilizan una valoración similar (bajo), lo que permite establecer que su propagación en el SSE es perjudicial para la oferta de SE.

La clasificación podría ser estructura ecológica metropolitana incorporó 14 coberturas de la tierra cuyo resultado de valoración integral estuvo entre el $17 \%$ y el $50 \%$. Estas coberturas son: red vial, ferroviaria y terrenos asociados $(3,6)$; zonas de disposición de residuos $(4,2)$; pastos limpios $(5,2)$; caña de azúcar $(5,3)$; plantación forestal $(8,3)$; cuerpos de agua artificiales $(9,7)$; y vegetación secundaria o en transición $(9,8)$.

Finalmente, 10 coberturas de la tierra fueron clasificadas como es estructura ecológica metropolitana -el resultado de su valoración fue mayor al 50\%- (Fig. 8): zonas verdes urbanas $(10,5)$; mosaico de cultivos, pastos y espacios naturales $(10,6)$; y mosaico de pastos con espacios naturales $(10,8)$. Las zonas verdes urbanas son las únicas coberturas seminaturales que pertenecen a la estructura ecológica metropolitana, dado que ofrecen diversos SE, principalmente de regulación y culturales. Por tal motivo, es importante reconocer su aporte al bienestar de la vida, particularmente al de la especie humana. La presencia de mosaicos como estructura ecológica metropolitana resalta la importancia de coberturas de la tierra con carácter múltiple en cuanto a la provisión de SE.

Las áreas húmedas continentales (humedales) proporcionan numerosos SE, entre los que se destacan el hábitat para especies, la regulación de la calidad del agua y el valor intrínseco de la existencia de la naturaleza. Este es un elemento de la estructura ecológica metropolitana de gran valor, pero, lastimosamente, cuenta con una extensión bastante reducida en el SEE. La cobertura de herbazales (páramo) proporciona agua dulce para todas las especies, regula el ciclo hidrológico y captura carbono del aire. Por esos y otros motivos, los páramos hacen parte de los ecosistemas más estratégicos del SSE. La cobertura de bosque denso puntuó de primero en los criterios, hecho que la coloca como el elemento más valioso de la estructura ecológica metropolitana -en términos ecosistémicos y por extensión- (Fig. 8).

Por último, la Figura 9 identifica la valoración de SE que proporciona la estructura ecológica metropolitana identificada al SSE "área de influencia metropolitana de Cali". En esta figura se observa que los elementos de la estructura ecológica metropolitana proporcionan, en orden descendente, SE de tipo cultural, de regulación y, por último, de aprovisionamiento. Esta situación refleja el reconocimiento de una estructura ecológica metropolitana multifuncional para la provisión de SE, en la cual todos sus elementos, siendo naturales o seminaturales, contribuyen de manera valiosa al bienestar de la vida en general, no solo de la especie humana. 


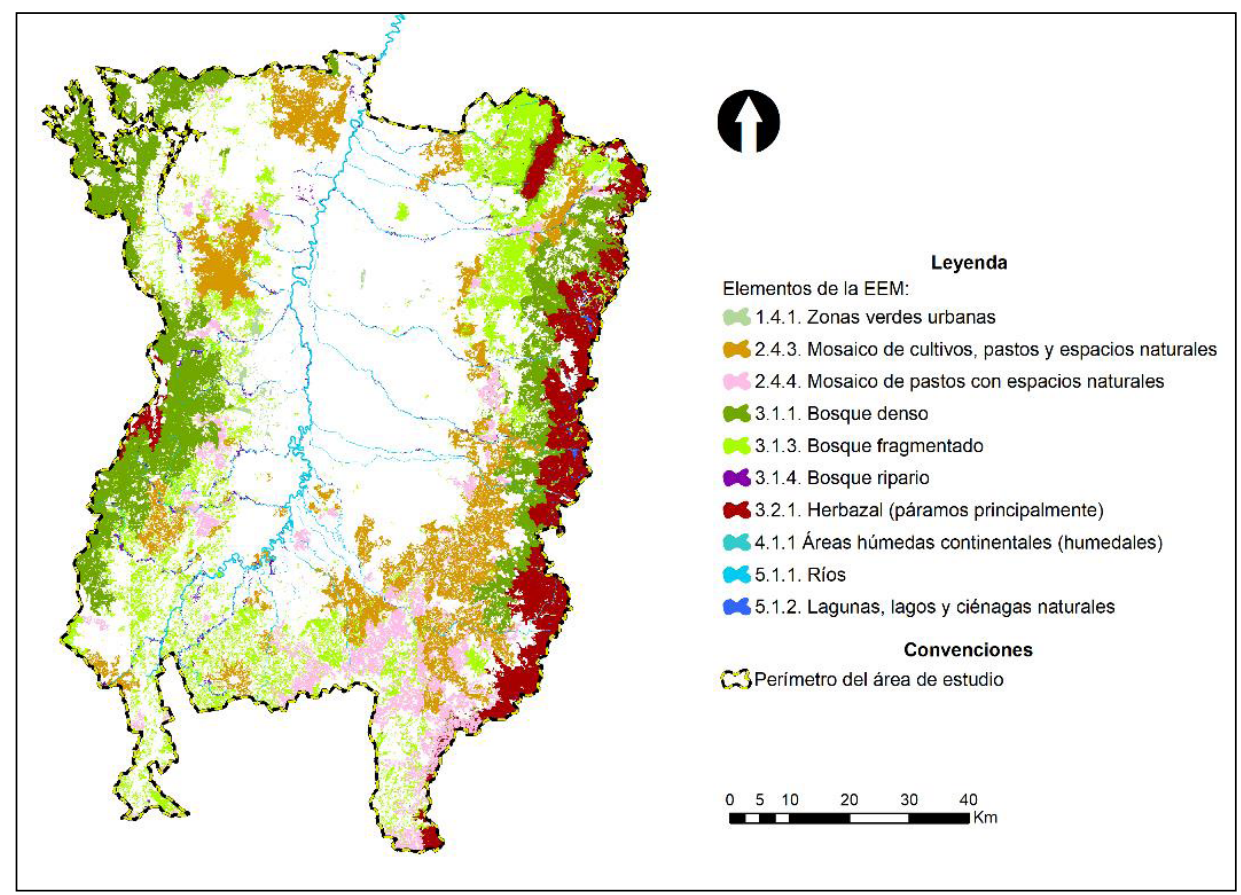

Figura 8. Coberturas que componen la estructura ecológica metropolitana del SSE. Fuente: elaboración propia.

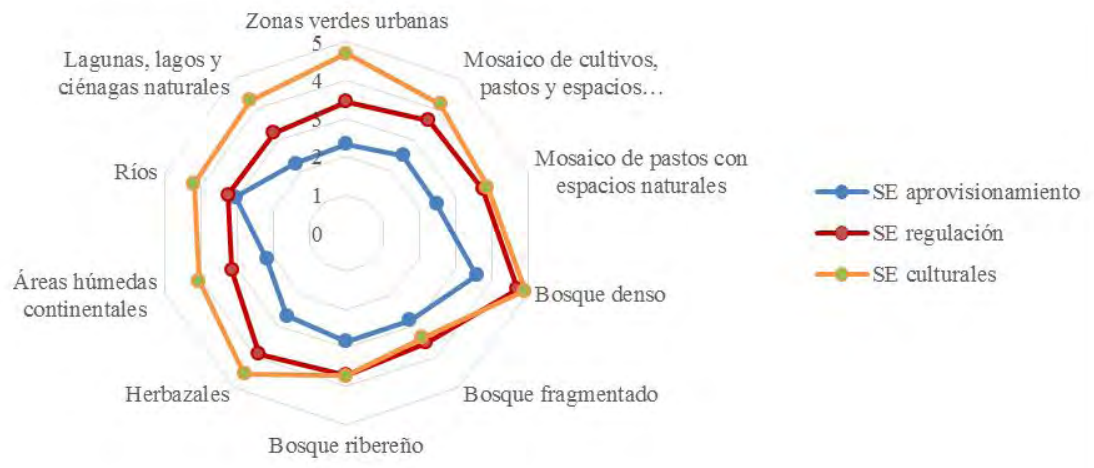

Figura 9. Esquema radial de oferta promedio de SE de los elementos de la estructura ecológica metropolitana. Fuente: elaboración propia. 


\section{Conclusiones}

Fue posible establecer una estructura ecológica metropolitana a partir de una metodología centrada en la valoración de SE, la cual se estima puede ser replicada en otras áreas metropolitanas. En este sentido, destacamos que la valoración de SE para el SSE “área de influencia metropolitana de Cali” y su uso para la identificación de la estructura ecológica metropolitana se convierte en una contribución transcendental hacia la consolidación del enfoque de servicios ecosistémicos en la planificación y gestión ambiental en la región. No se trata únicamente de un aporte para la academia, sino también para la administración pública -esto último, en términos de los valiosos hallazgos que servirán para la conformación de políticas ambientales acordes con las necesidades actuales-.

Además, es importante resaltar la pertinencia del uso de la unidad espacial "cobertura de la tierra" para identificar estructuras ecológicas metropolitanas. La cobertura de la tierra es una fuente de información fiable y real de la superficie terrestre, y su uso difiere de las técnicas tradicionales implementadas en el país, a partir de las cuales los elementos de las estructuras ecológicas municipales son presentados como ecosistemas, e incluso erradamente, como categorías normativas de protección ambiental. El nivel de precisión que brindan las coberturas de la tierra permite establecer claramente los tipos de SE que se pueden encontrar dentro de un área metropolitana determinada.

A través de la consulta a expertos se cuantificóla capacidad de los SEy se identificaron las coberturas de la tierra que los ofrecen y demandan. En este sentido, la zona plana del SSE -que concentra las actividades productivas, económicas y de servicios- es la demandante, mientras que las áreas ubicadas en la periferia -principalmente en las cordilleras Oriental y Occidental- son las ofertantes.

Por último, la determinación de la estructura ecológica metropolitana de SSE "área de influencia metropolitana de Cali" constituye un insumo clave para la formulación de lineamientos de planificación y gestión ambiental para el SSE identificado, ya que permite localizar las áreas de mayor oferta y demanda de SE. Para lograrlo de manera más efectiva, será necesario sobreponer estos resultados a las categorías de protección ambiental presentes en el SSE y analizar, entre otras cosas, su grado de cobertura en términos de área física. Este será uno de los objetivos de futuros trabajos del grupo de investigación "Territorios” de la Universidad del Valle, Colombia.

\section{Agradecimientos}

Los autores agradecen el financiamiento de la Vicerrectoría de Investigaciones de la Universidad del Valle, Colombia. También expresan su agradecimiento a Luis Felipe Gaitán, Alexander Bedoya, Anyerson Gómez, Diana Moreno, Marco Aguirre, Yolanda Otero y Zully Burbano, miembros del grupo de investigación "Territorios" que apoyaron el proyecto de investigación del cual se derivó este artículo. Gracias a su dedicación y esfuerzo fue posible realizar este trabajo de manera exitosa. Finalmente, los autores hacen una mención especial a Karolina Argote (Centro Internacional de Agricultura Tropical), Antonio Pantoja (Copandes), David Arango (Universidad Javeriana, sede 
Cali) y Leili Egea, quienes fueron un apoyo clave en temas relacionados con sensores remotos, programación, análisis estadísticos y redacción del artículo, respectivamente.

\section{Referencias}

Albert, C., Galler, C., Hermes, J., Neuendorf, F., Haaren, C. Von, Lovett, A. 2016. Applying ecosystem services indicators in landscape planning and management: The ES-in-Planning framework.Ecological Indicators 61, 100-113.https://doi.org/10.1016/j.ecolind 2015.03.029.

Boone, H. N., Boone, D. A. 2012. Analyzing Likert Data. Journal of Extension 50 (2), 5.

Burkhard, B., Kandziora, M., Hou, Y., Müller, F. 2014. Ecosystem service potentials, flows and demands-concepts for spatial localisation, indication and quantification. Landscape Online 34 (1), 1-32. https://doi.org/10.3097/LO.201434.

Burkhard, B., Kroll, F., Müller, F., Windhorst, W. 2009. Landscapes' capacities to provide ecosystem services - A concept for land-cover based assessments. Landscape Online 15 (1), 1-22. https://doi.org/10.3097/LO.200915.

Burkhard, B., Kroll, F., Nedkov, S., Müller, F. 2012. Mapping ecosystem service supply, demand and budgets. Ecological Indicators 21, 17-29. https://doi.org/10.1016/j.ecolind.2011.06.019.

Costanza, R., Arge, R., de Groot, R., Farber, S., Grasso, M., Hannon, B., Limburg, K., Naeem, S., O’Neill, R.V., Paruelo, J., Raskin, R.G., Sutton, P., van den Belt, M. 1997. The value of the world's ecosystem services and natural capital. Nature 387, 253-260. https://doi. org/10.1038/387253a0.

Cortinovis, C., Geneletti, D. 2018. Land Use Policy Ecosystem services in urban plans: What is there, and what is still needed for better decisions. Land Use Policy 70, 298-312. http://doi. org/10.1016/j.landusepol.2017.10.017.

Clason, D.L., Dormody, T.J. 1994. Analyzing Data Measured by Individual Likert-Type Items. Journal of Agricultural Education 35 (4), 31-35.

Cumming, G.S. 2011. Spatial Resilience in Social-Ecological Systems. Dordrecht: Springer. https://doi.org/10.1007/978-94-007-0307-0.

DANE 2009. Proyecciones nacionales y departamentales de poblacion 2005-2020. Estudios Postcensales. Bogotá, D.C., Departamento Administrativo Nacional de Estadisticas (DANE). http://doi.org/10.1017/CBO9781107415324.004.

EEA 2011. Green infrastructure and territorial cohesion. Technical Report 18. European Environment Agency, Copenhagen.

ESRI 2017. Train Random Trees Classifier. Disponible en: http://desktop.arcgis.com/en/arcmap/ latest/tools/spatial-analyst-toolbox/train-random-trees-classifier.htm (Fecha de acceso: 28/02/2017).

Fisher, B., Turner, R.K., Morling, P. 2009. Defining and classifying ecosystem services for decision making. Ecological Economics 68 (3), 643-653. .https://doi.org/10.1016/j. ecolecon.2008.09.014

Folke, C. 2006. Resilience: The emergence of a perspective for social-ecological systems analyses. Global Environmental Change 16 (3), 253-267. https://doi.org/10.1016/j. gloenvcha.2006.04.002.

Gligo, N. 1995. Entorno de la sustentabilidad ambiental del desarrollo agrícola latinoamericano: factores y políticas. En: G.C. Gallopín (Ed.), El futuro ecológico de un continente: una visión prospectiva de la América Latina (p. 336) México, D.F., Universidad de las Naciones Unidas, $336 \mathrm{pp}$.

Google 2017. Google Forms. Disponible en: https://www.google.com/forms/about/ (Fecha de acceso: 08/08/2017). 
Goodland, R. 1995. The concept of environmental sustainability. Annual Review of Ecology, and Systematics 26, 1-24.

Gulinck, H., Múgica, M., de Lucio, J.V., Atauri, J.A. 2001. A framework for comparative landscape analysis and evaluation based on land cover data, with an application in the Madrid region (Spain). Landscape and urban planning 55 (4), 257-270.

Haines-Young, R., Potschin-Young, M. 2013. Common International Classification of Ecosystem Services (CICES, Version 4.3). Report to the European Environment Agency, (September), 17 pp.

Haines-Young, R. Potschin, M. 2017. The classification challenge. En: B. Burkhard, J. Maes, (Eds.), Mapping Ecosystem Services, Pensoft, Sofia, pp. 42-45.

Harvey, D. 2008. The right to the city. The New Left Review 53, 23-40.

Helliwell, D.R. 1969. Valuation of wildlife resources. Regional studies 3 (1), 41-47.

IDEAM 2010. Leyenda nacional de coberturas de la tierra. Metodología CORINE Land Cover adaptada para Colombia Escala 1:100.000. Bogotá, D.C., Instituto de Hidrología, Meteorología y Estudios Ambientales.

Instituto Geográfico Agustín Codazzi (IGAC) 2018. Formatos y Escalas de Mapas. Recuperado 18 de mayo de 2018, a partir de https://www.igac.gov.co/es/contenido/areas-estrategicas/ formatos-y-escalas-de-mapas.

Holling, C.S. 2001. Understanding the Complexity of Economic, Ecological, and Social Systems. Ecosystems 4 (5), 390-405. https://doi.org/10.1007/s10021-00.

Hughes, H. 1993. Metropolitan Structure and the Suburban Hierarchy. American Sociological Review 58 (3), 417-433. https://www.jstor.org.bd.univalle.edu.co/stable/2095909.

Jacobs, S., Burkhard, B., Van Daele, T., Staes, J., Schneiders, A. 2015. "The Matrix Reloaded”: A review of expert knowledge use for mapping ecosystem services. Ecological Modelling 295, 21-30. http://doi.org/10.1016/j.ecolmodel.2014.08.024.

Jacobs, S., Burkhard, B. 2017. Applying expert knowledge for ecosystem services quantification. En: B. Burkhard, J. Maes (Eds.) Mapping Ecosystem Services. Pensoft, Sofía, pp. 142-146.

Kaczorowska, A., Jaan-Henrik, K., Jakub, K., Dagmar, H. 2016. Ecosystem services in urban land use planning: Integration challenges in complex urban settings - Case of Stockholm. Ecosystem Services 22, 204-212. https://doi.org/10.1016/j.ecoser.2015.04.006.

Koschke, L., Fürst, C., Frank, S., Makeschin, F. 2012. A multi-criteria approach for an integrated land-cover-based assessment of ecosystem services provision to support landscape planning. Ecological Indicators 21, 54-66. http://doi.org/10.1016/j.ecolind.2011.12.010.

Marques, L Pradilla, E., 2008. Desindustrialización, terciarización y estructura metropolitana: un debate conceptual necesario. Cuadernos del CENDES 69, 21-45.

Martínez-Toro, P. 2014. La producción del espacio en la ciudad latinoamericana. El modelo del impacto del capitalismo global en la metropolización. Hallazgos 12 (23), 1794-3841. https:// doi.org/10.15332/s1794-3841.2015.0023.010.

Martínez-Toro, P. 2014. La planificación y la gestión interescalar municipal y metropolitana: casos áreas metropolitanas de Valle de Aburrá y Centro Occidente. Santiago de Cali: Universidad del Valle, Programa Editorial.

Martínez-Toro, P. 2018. Mercado inmobiliario y la producción del archipiélago metropolitano. La metropolización de Cali. Bitácora Urbano Territorial 28 (1), 9-24. https://doi.org/10.15446/ bitacora.v28n1.40237.

Martínez-Toro, P., Buitrago-Bermúdez, O. 2011. Cali: una metrópoli regional en movimiento. La planeación municipal y los procesos de metropolización. Santiago de Cali: Universidad del Valle, Programa Editorial.

Martínez-Toro, P., Patiño-Gómez, Z.L. 2015. Área metropolitana del sur del Valle y norte del Cauca (AMVACA). Definición, caracterización y propuesta de conformación. Santiago de Cali: Universidad del Valle, Programa Editorial. 
Millennium Ecosystem Assessment. 2005. Ecosystems and Human Well-being: Synthesis. Washington, D.C., Island Press.

NASA Jet Propulsion Laboratory 2009. ASTER Global Digital Elevation Model. Disponible en: https://gdex.cr.usgs.gov/gdex/ (Fecha de acceso: 01/04/2016).

Nedkov, S., Bayona, K., Burkhard, B. 2015. Quantifying, Modelling and Mapping Ecosystem Services in Watersheds. En: L. Chicharo, F. Müller, N. Fohrer (Eds.), Ecosystem Services and River Basin Ecohydrology. Springer, pp. 133-149. https://doi.org/10.1007/978-94-0179846-4.

Potschin, M., Haines-Young, R. 2013. Landscapes, sustainability and the place-based analysis of ecosystem services. Landscape Ecology 28 (6), 1053-1065.

Potschin, M., Haines-Young, R. 2017. From nature to society. En: B. Burkhard, J. Maes (Eds.), Mapping Ecosystem Services. Sofia, Pensoft, pp. 39-41.

Rojas, E., Cuadrado-Roura, J.R., Fernández Güell, J.M. 2005. Gobernar las metrópolis. Washington, D.C.

Salas-Zapata, W.A., Ríos-Osorio, L.A., Álvarez-del Castillo, J. 2012. Marco conceptual para entender la sustentabilidad de los sistemas socioecológicos. Ecologia Austral 22 (1), 74-79.

Salitchev, K. 2009. Cartografía. Pueblo y Educación. La Habana.

Satir, O. Berberoglu, S. 2012. Land use/cover classification techniques using optical remotely sensed data in landscape planning. En: M. Ozyavuz (Ed.). Landscape Planning, InTech, pp. 21-54.

Stanford University 2017. Matrix Operations. Disponible en: http://doi.org/q (Fecha de acceso 13/09/2017).

Stephens, G. R., Wikstrom, N. 2000. Metropolitan government and governance. Oxford University Press, $208 \mathrm{pp}$.

Tabares-Mosquera,M., Gaitán-Idárraga,L.F. 2018. Estructura ecológica del sistema socioecológico “área de influencia metropolitana de Santiago de Cali”. Universidad del Valle.

van der Hammen, T., Andrade, G. 2003. Estructura ecológica principal de Colombia: Primera aproximación. Bogotá, D.C., IDEAM.

Woodruff, S.C., Bendor, T.K. 2016. Landscape and Urban Planning Ecosystem services in urban planning: Comparative paradigms and guidelines for high quality plans. Landscape and Urban Planning 152, 90-100. https://doi.org/10.1016/j.landurbplan.2016.04.003.

\section{Material suplementario}

2.1. Preguntas relativas a la provisión de servicios ecosistémicos. Dirigidas a los expertos identificados para los grupos temáticos "bosques y "áreas seminaturales", "áreas de producción agrícola" y "áreas húmedas":

\section{Aprovisionamiento de nutrición}

1. ¿Qué capacidad tienen estas coberturas para proveer "biomasa para alimentación"?

2. ¿Qué capacidad tienen estas coberturas para proveer "agua para consumo humano"?

\section{Aprovisionamiento de materiales}

3. ¿Qué capacidad tienen estas coberturas de proveer "materiales a partir de biomasa"? 
4. ¿Qué capacidad tienen estas coberturas de proveer "agua como materia prima”?

5. ¿Qué capacidad tienen estas coberturas de proveer “materiales metálicos y no metálicos"?

\section{Aprovisionamiento de energía}

6. ¿Qué capacidad tienen estas coberturas de proveer "biomasa para producir energía"?

7. ¿Qué capacidad tienen estas coberturas de proveer "energía renovable"?

8. ¿Qué capacidad tienen estas coberturas de proveer "energía no renovable"?

Regulación y mantenimiento: regulación de residuos, sustancias tóxicas y otras molestias

9. ¿Qué capacidad tienen estas coberturas para contribuir a la "regulación de residuos y sustancias tóxicas"?

Regulación y mantenimiento: regulación de flujos

10. ¿Qué capacidad tienen estas coberturas para contribuir a la "regulación de los flujos de masa"?

11. ¿Qué capacidad tienen estas coberturas para contribuir a la "regulación de los flujos de líquido"?

12. ¿Qué capacidad tienen estas coberturas para contribuir a la "regulación de los flujos de aire"?

Regulación y mantenimiento: mantenimiento de condiciones físicas, químicas y biológicas

13. ¿Qué capacidad tienen estas coberturas para contribuir al "mantenimiento del ciclo de vida y hábitat"?

14. ¿Qué capacidad tienen estas coberturas para contribuir al "control de plagas y enfermedades"?

15. ¿Qué capacidad tienen estas coberturas para contribuir a la "formación y composición del suelo"?

16. ¿Qué capacidad tienen estas coberturas para contribuir al "mantenimiento de la composición química del agua"?

17. ¿Qué capacidad tienen estas coberturas para contribuir a la "regulación del clima y la composición atmosférica"?

Servicios ecosistémicos culturales: interacción física e intelectual

18. ¿Qué capacidad tienen estas coberturas para contribuir a la "interacción y experiencia física con la naturaleza"?

19. ¿Qué capacidad tienen estas coberturas para contribuir a la "interacción intelectual y representativa con la naturaleza"? 
Servicios ecosistémicos culturales: interacción simbólica y espiritual

20. ¿Qué capacidad tienen estas coberturas para contribuir a la "interacción espiritual y emblemática con la naturaleza"?

21. ¿Qué capacidad tienen estas coberturas para contribuir al "reconocimiento de la existencia y el valor intrínseco de la naturaleza"?

2.2. Preguntas relativas a la demanda de servicios ecosistémicos. Dirigidas a los expertos identificados para el grupo temático "áreas artificializadas":

\section{Aprovisionamiento de nutrición}

1. ¿Cuál es el nivel de demanda de "biomasa para alimentación” de estas coberturas de la tierra?

2. ¿Cuál es el nivel de demanda de "agua para consumo humano" de estas coberturas de la tierra?

\section{Aprovisionamiento de materiales}

3. ¿Cuál es el nivel de demanda de "materiales a partir de biomasa" de estas coberturas de la tierra?

4. ¿Cuál es el nivel de demanda de "agua como materia prima" de estas coberturas de la tierra?

5. ¿Cuál es el nivel de demanda de "materiales metálicos y no metálicos" de estas coberturas de la tierra?

Aprovisionamiento de energía

6. ¿Cuál es el nivel de demanda de "biomasa para producir energía” de estas coberturas de la tierra?

7. ¿Cuál es el nivel de demanda de "energía renovable" de estas coberturas de la tierra?

8. ¿Cuál es el nivel de demanda de "energía no renovable" de estas coberturas de la tierra?

Regulación y mantenimiento: regulación de residuos, sustancias tóxicas y otras molestias

9. ¿Cuál es el nivel de demanda de estas coberturas de la tierra en cuanto a "regulación de residuos y sustancias tóxicas"?

Regulación y mantenimiento: regulación de flujos

10. ¿Cuál es el nivel de demanda de estas coberturas de la tierra en cuanto a "regulación de los flujos de masa"?

11. ¿Cuál es el nivel de demanda de estas coberturas de la tierra en cuanto a "regulación de los flujos de líquido"? 
12. ¿Cuál es el nivel de demanda de estas coberturas de la tierra en cuanto a "regulación de los flujos de aire"?

Regulación y mantenimiento: mantenimiento de condiciones físicas, químicas y biológicas

13. ¿Cuál es el nivel de demanda de "mantenimiento del ciclo de vida y hábitat" de estas coberturas de la tierra?

14. ¿Cuál es el nivel de demanda de "control de plagas y enfermedades" de estas coberturas de la tierra?

15. ¿Cuál es el nivel de demanda de "formación y composición del suelo" de estas coberturas de la tierra?

16. ¿Cuál es el nivel de demanda de "mantenimiento de la composición química del agua" de estas coberturas de la tierra?

17. ¿Cuál es el nivel de demanda de "regulación del clima y la composición atmosférica" de estas coberturas de la tierra?

Servicios ecosistémicos culturales: interacción física e intelectual

18. ¿Cuál es el nivel de demanda de estas coberturas de la tierra en cuanto a "interacción y experiencia física con la naturaleza"?

19. ¿Cuál es el nivel de demanda de estas coberturas de la tierra en cuanto a "interacción intelectual y representativa con la naturaleza"?

Servicios ecosistémicos culturales: interacción simbólica y espiritual

20. ¿Cuál es el nivel de demanda de estas coberturas de la tierra en cuanto a "interacción espiritual y emblemática con la naturaleza"?

21. ¿Cuál es el nivel de demanda de estas coberturas de la tierra en cuanto al "reconocimiento de la existencia y el valor intrínseco de la naturaleza"? 